\title{
Spectrum of Preterm Birth in Tertiary Care Hospital in Shimla District of Himachal Pradesh
}

\author{
Kiran Azad $^{1}$, Deepak Sharma ${ }^{2}$, Ambika Sood ${ }^{3}$, Rakesh Sharma ${ }^{4}$, Sanya Sharma ${ }^{5}$ \\ ${ }^{1}$ Pediatrician, CH Manali, Himachal Pradesh \\ ${ }^{2} \mathrm{MMU}$, Medical College, Solan \\ ${ }^{3}$ Senior Resident, Department of Pediatrics, Indira Gandhi Medical College, Shimla \\ ${ }^{4}$ Prof \& Head, Department of Pediatrics, Indira Gandhi Medical College, Shimla \\ ${ }^{5}$ SLBS, Medical College, Mandi \\ Corresponding Author: Ambika Sood
}

DOI: https://doi.org/10.52403/ijrr.20220216

\begin{abstract}
Background: Globally, Prematurity or preterm birth is the leading cause of death in under the age of 5 years but this has been often overlooked and neglected problem. The present study aimed to study the trends of preterm birth in Shimla district of Himachal Pradesh, India.

Methods: Retrospective review of records of Kamla Nehru Hospital, Shimla covering the period January 2016 to December 2020 was conducted. The total number of preterm birth were retrieved.
\end{abstract}

Results: A total of 34769 live birth took place in Kamla Nehru Hospital, Shimla from 2016 to 2020. Among the total live births, 5654(16.26\%) were premature birth $(<37$ weeks $)$ while $29115(83.74 \%)$ were term birth. There was continuous decline in premature birth from $32.24 \%$ in 2016 to $17.41 \%$ in 2017 and $10.84 \%$ in 2018 , slightly rose to $10.87 \%$ in 2019 and $11.75 \%$ in 2020

Conclusions: The study concluded that over a period of 5 years there was continuous decrease in premature birth and now it reached almost near to the global average of preterm birth.

Key Words: Trends, Preterm birth, Kamla Nehru Hospital, Shimla

\section{INTRODUCTION}

Preterm birth is defined as "all births before 37 completed weeks of gestation or less than 259 days since the 1st day of a woman's last menstrual period" as per World health Organization(WHO). ${ }^{1}$
Globally, Preterm Birth (PTB) is the single major and largest cause of neonatal deaths. Worldwide, approximately 15 million babies are born preterm per year, indicating a global PTB of about 11 percent. With nearly, one million children dying due to preterm birth before five years of age, preterm birth (PTB) is a significant reason of mortality among children, accounting for almost 18 percent of all deaths among children aged under five years of age and as much as 35percent of all deaths among newborns (aged less than 28 days). There are significant variations in preterm birth rates (PTB) as well as mortality between countries, especially between high and lowmiddle income countries, and even intracountry variations have been observed especially in a country like ours. However, the burden of preterm birth is proportionally more in low \& middle-income countries, especially in the sub-Saharan African and Southeast Asian regions. ${ }^{2,3}$

In country like India, of the 27 million babies born annually, 3.6 million babies are born preterm and over 300,000 of these preterm babies die every year due to associated complications. India, with its highest number of PTBs and the highest number of preterm deaths worldwide, contributes almost 25 percent of the overall preterm related deaths globally. Despite substantial efforts to introduce new 
therapies for its prevention, it continues to contribute significantly to neonatal as well as infant mortality. The effects of Preterm birth extend beyond the early infancy with having long-term consequences in late childhood and further in adult life. ${ }^{4,5}$

New-born babies constitute one of the most vulnerable groups even if born healthy \& at term. Prematurity makes them even more susceptible to poor health outcomes. Prematurity is the leading reason of death in children less than 5 years of age across the globe. In recent years, the trend from most countries which have reliable data collection shows that the rate of preterm birth is on the higher side. Out of the total 15 million babies born preterm, one million do not survive. Among those who do survive, many suffer from various lifelong disabilities including hearing loss \& visual problems. In the developed countries, 9 out of 10 extreme preterm babies survives; whereas in low income developing countries including Sub Saharan Africa and Southeast Asia regions, only 1 out of 10 extreme preterms survives. ${ }^{6,7}$

This issue of prematurity or preterm birth (PTB) is of extremely significance for achieving the United Nation's Sustainable Development Goal 3 (SDG-3) target \#3.2, which aims to prevent and end all preventable deaths among newborns \& children $<5$ years of age by the year $2030 .^{2,8}$

There is a paucity of data regarding preterm birth rates in Shimla, and Himachal Pradesh. Against this backdrop, the study was conducted to see the trends of preterm births at Kamla Nehru Hospital associated with Indira Gandhi Medical College and Hospital from the year 2016 to 2020.

\section{Objectives of the Study}

To study the trends of preterm births at Kamla Nehru Hospital associated with Indira Gandhi Medical College and Hospital from the year 2016 to 2020 .

\section{RESEARCH METHODOLOGY}

A retrospective institutional based, descriptive study was done in Kamla Nehru Hospital, Shimla, of a period of $5 \mathrm{yrs}$, between January 2016 to December 2020. All deliveries conducted in the institution during this period were included. Ethical permission was obtained from the concerned authorities. The data was collected from the record files, compiled and entered in MS Excel, and analyzed using appropriate statistical tools in software Epi info V7 by applying appropriate statistical tests in terms of frequencies and percentage

\section{RESULTS}

A retrospective review of Kamla Nehru Hospital records was conducted for a period of 5 years from January 2016 to December 2020. All pregnant women who delivered at Kamla Nehru Hospital, Shimla, Himachal Pradesh, during the study period were included.

A total of 34769 live births occurred in Kamla Nehru Hospital, Shimla from 2016 to 2020. Among the total live births, $5654(16.26 \%)$ were premature birth $(<37$ weeks) while $29115(83.74 \%)$ were term birth. (Table-1)

\begin{tabular}{|c|c|c|c|c|c|c|c|c|c|c|c|c|}
\hline Year & 2016 & $\%$ & 2017 & $\%$ & 2018 & $\%$ & 2019 & $\%$ & 2020 & $\%$ & Total & $\%$ \\
\hline & 4381 & 67.76 & 5428 & 82.59 & 6129 & 89.16 & 6542 & 89.13 & 6635 & 88.25 & 29 & 83.74 \\
\hline & 208 & 32.24 & 11 & 17. & 745 & 10. & 79 & 7 & 88 & 11 & 2 & 16.26 \\
\hline Total Live birth & 6465 & 100.0 & 6572 & 100.0 & 6874 & 100.0 & 7340 & 100.0 & 7518 & 100.0 & 34769 & 100.0 \\
\hline
\end{tabular}

Upon further review we found that there was continuous decline in preterm birth from $32.24 \%$ in 2016 to $17.41 \%$ in
2017 and $10.84 \%$ in 2018 , after which it rose slightly to $10.87 \%$ in 2019 and $11.75 \%$ in 2020.(Figure-1) 


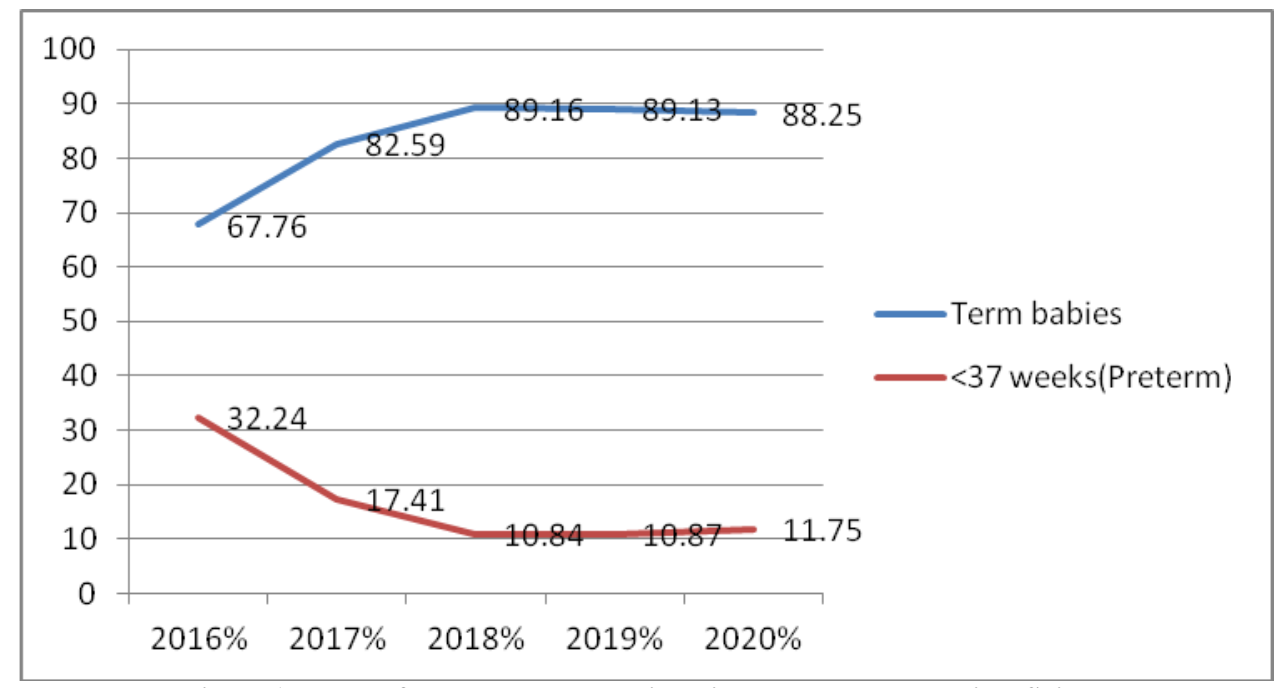

Figure-1: Trend of term and preterm births in Kamla Nehru Hospital, Shimla

\section{DISCUSSION}

Preterm birth happens for a variety of reasons. Most preterm births occur spontaneously, but few are either due to early induction of labor or due to caesarean birth, whether it is for medical or nonmedical reasons. Some common causes of preterm birth include multiple pregnancies, infections \& chronic disease conditions like diabetes and high blood pressure; however, often no specific cause is identified. There could be a genetic influence also. Better understanding of these causes \& mechanisms will further advance the development of solutions to prevent preterm birth. ${ }^{1,9}$

In the present study, we found that there was continuous decline in premature birth from $32.24 \%$ in 2016 to $17.41 \%$ in 2017 and $10.84 \%$ in 2018 , followed by a slightly increase to $10.87 \%$ in 2019 and $11.75 \%$ in 2020 which is almost close to the global average of preterm birth. The high rate of preterm birth in our institute could be attributed to the fact that it is a tertiary institute with referrals from all over the state for varied medical or surgical reasons.

In all 184 countries, the rate of preterm birth ranges from 5 percent to 18 percent. In the lower- or middle-income countries, on an average, 12 percent of babies are born too early as compared with 9 percent in higher income countries. ${ }^{9,10}$
Preventing the deaths and further complications from preterm birth start with a healthy pregnancy. Quality of care before, between and during pregnancies will often ensure all females have a positive pregnancy experience and a positive outcome. WHO's antenatal care (ANC) guidelines include key interventions, which help in preventing preterm birth, such as counseling on healthy diet \& optimal nutrition, and tobacco \& substance abuse, fetal measurements including use of ultrasound to help estimating gestational age and detecting multiple pregnancies and a minimum of eight contacts with health professionals throughout the pregnancy to identify and further manage risk factors, like infections and chronic diseases. Better access to contraceptives \& increased women empowerment could also help in reducing preterm births. ${ }^{7,11,12}$

More than $3 / 4^{\text {th }}$ of premature babies can be saved with feasible \& cost-effective care, like essential care during child-birth as well as in the postnatal period for every mother and her baby, provision of appropriate antenatal steroidal injections ( to improve lung maturity), kangaroo mother care and appropriate antibiotics to treat newborn infections. Essential newborn care (drying, warming, immediate \& exclusive breastfeeding, hygiene \& cord care) as well as basic care for feeding \& nutritional support, infections and breathing difficulties 
can mean the difference between life \& death for these preterm babies. ${ }^{1,9,13}$

\section{CONCLUSION}

Over a period of years there has been a continuous decline in preterm birth rate and now has reached almost near to the global average of preterm birth. More efforts are needed to identify women at the risk of preterm labor and further support them to give birth in a health facility that can offer an extra care whenever needed, such as support for adequate feeding with breast milk, continuous skin to skin contact (KMC), antibiotics and appropriate antenatal corticosteroids. To do these, it is critical that families, communities, and health care workers value the small babies so that they receive lifesaving care they really need. To turn the tide on these preventable deaths, we must need action across the spectrum of care right from adolescent period and then preconception, pregnancy, the safe management of labor \& delivery, then finally effective immediate \& later postnatal care.

\section{Recommendation}

One important and significant reason for our inability to reduce the burden of prematurity or preterm birth is that the causes and risk factors of preterm birth (PTB) are not fully understood. Without a clear understanding of the causes and risk factors, it is hardly possible to predict and therapeutically prevent these preterm births. The information provided here can be utilized to understand the current situation \& pattern, increase attention to preterm births in Himachal Pradesh and to inform dialogue and further action among stakeholders to understand the causes of preterm birth.

\section{Acknowledgement: None}

Conflict of Interest: None

Source of Funding: None

\section{Ethical Approval: Approved}

\section{REFERENCES}

1. National Health Portal. Available at: https://www.nhp.gov.in/disease/reprodu ctive-system/female-gynaecologicaldiseases-/preterm-birth (Accessed on 13 June 2021)

2. Walani SR. Global burden of preterm birth. Int J Gynaecol Obstet. 2020 Jul;150(1):31-33

3. Lawn, J.E., Gravett, M.G., Nunes, T.M. et al. Global report on preterm birth and stillbirth (1 of 7): definitions, description of the burden and opportunities to improve data. BMC Pregnancy Childbirth,2010; 10:S1.

4. National Institute of Biomedical Genomics. Available at: https://www.nibmg.ac.in/?q=content/pre term-birth-program. (Accessed on 15 June 2021)

5. Economic Times. Available at: https://economictimes.indiatimes.com/in dustry/healthcare

/biotech/healthcare/programmelaunched-to-identify-causes-ofprematurebirths/articleshow/41526496.cms?from= mdr (Accessed on 16 June 2021)

6. Glass HC, Costarino AT, Stayer SA, Brett CM, Cladis F, Davis PJ. Outcomes for extremely premature infants. Anesth Analg. 2015;120(6):1337-1351.

7. Center of disease prevention \& Control. Available at: https://www.cdc.gov/reproductivehealth/ maternalinfanthealth/pretermbirth.htm (Accessed on 17 June 2021)

8. World Health Organization. Available at:

https://apps.who.int/iris/handle/10665/2 08280 (Accessed on 17 June 2021)

9. World Health Organization. Available at: https://www.who.int/news-room/factsheets/detail/preterm-birth (Accessed on 17 June 2021)

10. Blencowe, H., Cousens, S., Chou, D. et al. Born Too Soon: The global 
epidemiology of 15 million preterm births. Reprod Health ,2013;10:S2 .

11. UNICEF. Available at: https://www.unicef.org/india/what-wedo/maternal-health (Accessed on 18 June 2021)

12. Requejo J, Merialdi M, Althabe F, Keller M, Katz J, Menon R. Born too soon: care during pregnancy and childbirth to reduce preterm deliveries and improve health outcomes of the preterm baby. Reprod Health. 2013;10 Suppl 1(Suppl 1):S4.
13. Community medicine 4 all. Available at: https://communitymedicine4all.com/201 7/11/18/who-updates-fact-sheet-onpreterm-birth-16-november2017/(Accessed on 18 June 2021)

How to cite this article: Azad K, Sharma D, Sood A. Spectrum of preterm birth in tertiary care hospital in Shimla district of Himachal Pradesh. International Journal of Research and Review. 2022; 9(2): 112-116. DOI: https://doi.org/10.52403/ijrr.20220216 